\title{
Minimizing the Loses of Solar Power Generation by Designing an Intelligent Tracking System Implemented on FPGA
}

\author{
Alaa Hamza Omran \\ Department of Information System Management, University of Information Technology and Communications, Iraq
}

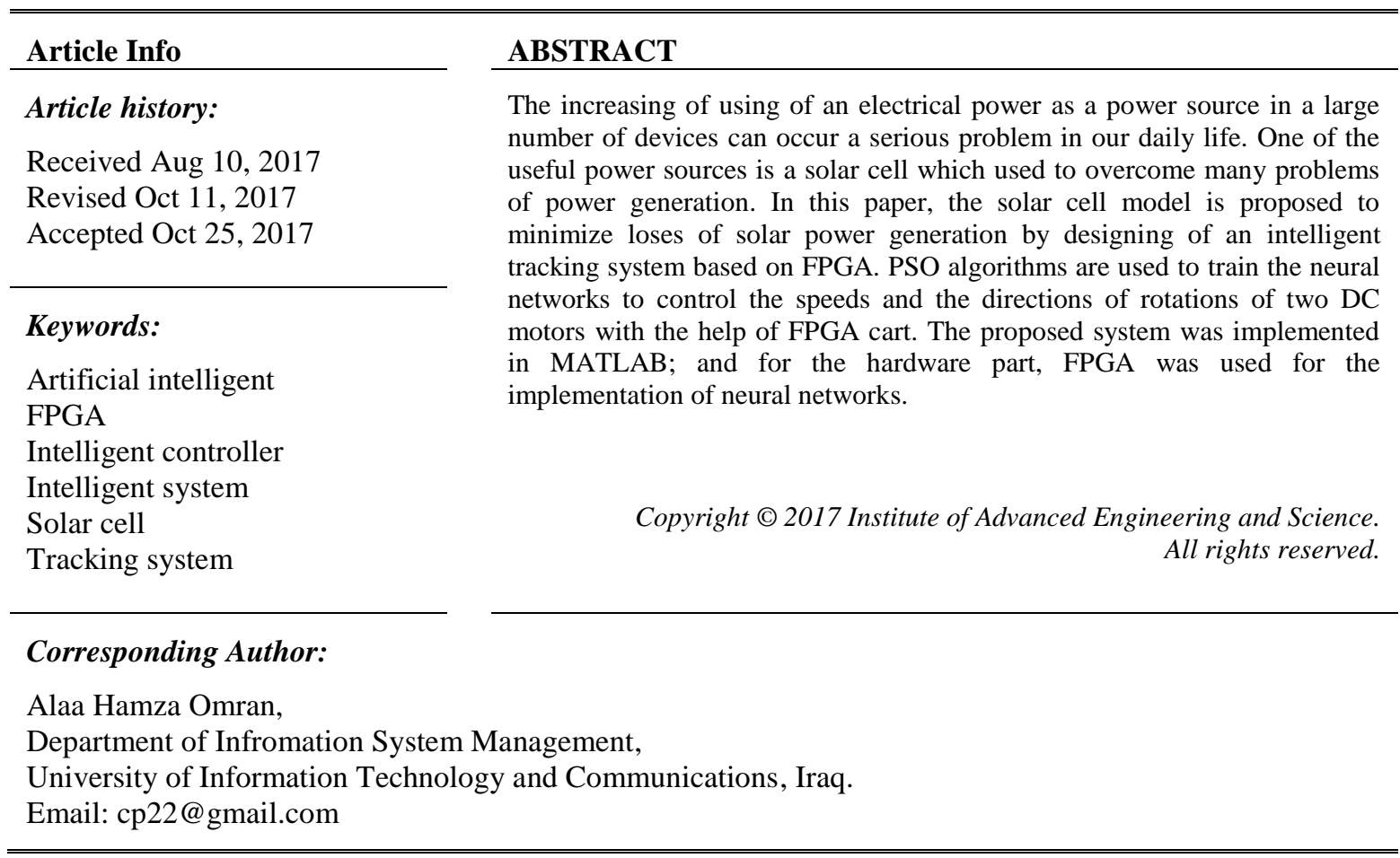

\section{INTRODUCTION}

Energy which replenished continuously and produced by natural resources such as sunlight, geothermal and tides, wind etc., can never be fatigued [1]-[4]. Thus, it is considered as unlimited resources. There are many benefits of using it as compared with conventional fossil fuels resources such as the ability of reduction of pollution level as considered a clean power source. Nowadays, most energy resources produced by combustion of fossil fuels such as natural gas, oil, coal etc. [5]. Recently, the increasing in demand on the electrical power for daily use leads to many problems. However, the electric energy is not replenished which means the daily used of this energy can leads to terminate it. Therefore, the demand on clean and replenished energy is increased such as renewable energy. Solar energy is considered as a good power source in many practical applications due to its widely existing in the earth and the simplicity of converting it to the electrical power [6].

As knowing, the solar cells are affected by many internal factors such as the type of material which used in the solar cell industry and also many external factors such as the intensity of the light and the temperature which falls on the cells and others [7]. Because of the cost of the changing in the internal factors is somewhat expensive, the aim of this research was to control the external factors that affect the productivity of the solar cell for the electrical energy. An intelligent controller was proposed and designed to direct the solar cell towards the sunlight to increasing the production of the solar cell as much as possible.

\section{MATHEMATICAL MODEL OF PV CELL}

From the physical behavior of a photovoltaic cell and based on the sensitivity of the semiconductor material to the sunlight, ideal solar cell, theoretically, can be modeled as a current source in anti-parallel with 
a diode Figure 1 shows the equivalent circuit. When the cell is exposed to light the direct current will be generated and varies linearly with solar radiation [8].

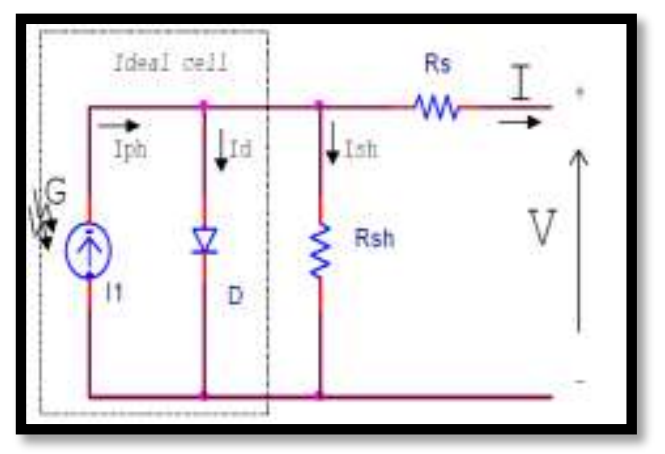

Figure 1. Photovoltaic cell equivalent circuit

Solar cell can be modeled in one diode parallel with current source model or can be modeled in two diode parallel with current source model [9].

\subsection{Solar Model for One Diode}

Based on the equivalent circuit of photovoltaic panel and for ideal cell its characteristic equation is

$$
I=I p h-I d
$$

where $: I$ is the current out from cell

Iphis a light-generated current or photocurrent,

$$
I p h=I s c+K I(T C-T R e f) * \frac{G}{G n}
$$

where : Iscis the cell's short-circuit current at a $25^{\circ} \mathrm{C}$ and $1 \mathrm{~kW} / \mathrm{m} 2$

$K I$ is the cell's short-circuit current temperature coefficient,

$T C=$ is the cell's working temperature.

$T R e f$ is the cell's reference temperature

$G$ is the surface irradiance of the cell and

Gn Nominal irradiance [W/m^2] at 25oC; $\mathrm{Gn}=1000$

Idis diode current and it is equals to:

$I d=I o *\left[e^{\frac{q *(V+I R S)}{K * T C * A}}-1\right]$

Iois the cell saturation of dark current

$$
I o=I R s *\left(\frac{T C}{T r e f}\right)^{3} *\left[e^{\frac{q * E G(T C-T r e f)}{\operatorname{Tref*TC*K*A}}}\right]
$$

where : IRsis the cell's reverse saturation current at a reference temperature and standard solar radiation.

EGis the bang-gap energy of the semi-conductor used in the cell and.

$A$ is the ideal factor, dependent on PV technology.

$q=(1.6 \times 10-19 \mathrm{C})$ is an electron charge.

$k=(1.38 \times 10-23 \mathrm{~J} / \mathrm{K})$ is a Boltzmann's constant.

An improved equation which considers temperature variations in order to describe the saturation current is given by [10]

$$
\mathrm{Io}=\frac{\mathrm{Isc}+\mathrm{KI} *(\mathrm{TC}-\mathrm{TRef})}{\exp \left[\frac{\mathrm{Voc}+\mathrm{KV} *(\mathrm{TC}-\mathrm{TRef})}{\mathrm{A} * \mathrm{Vt}}\right]-1}
$$


Vocis cell's open circuit voltage

$$
V t=\frac{\mathrm{NS} * \mathrm{~K} * \mathrm{TC} * \mathrm{~A}}{\mathrm{q}}
$$

NSis the number of series cells So,

$$
\mathrm{I}=\left[I S C+K I(T C-T R e f) * \frac{G}{G n}\right]-\left[\frac{\mathrm{Isc}+\mathrm{KI} *(\mathrm{TC}-\mathrm{TRef})}{\exp \left[\frac{\mathrm{Voc}+\mathrm{KV} *(\mathrm{TC}-\mathrm{TRef})}{\mathrm{A} * \mathrm{Vt}}\right]-1}\right] *\left[e^{\frac{q *(V+I R S)}{K * T C * A}}-1\right]
$$

An improvement of the model includes the effects of a shunt resistance (Rsh) and another in series $(R S)$. The output current will be:

$$
\begin{aligned}
& I=I p h-I d- \\
& \mathrm{I}=\left[I S C+K I(T C-T R e f) * \frac{G}{G n}\right]-\left[\frac{\mathrm{Isc}+\mathrm{KI} *(\mathrm{TC}-\mathrm{TRef})}{\exp \left[\frac{\mathrm{VOC}+\mathrm{KV} *(\mathrm{TC}-\mathrm{TRef})}{\mathrm{A} * \mathrm{Vt}}\right]-1}\right] *\left[e^{\frac{q *(V+I R S)}{K * T C * A}}-1\right]-\left[\frac{(\mathrm{V}+\mathrm{IRs})}{\mathrm{Rsh}}\right]
\end{aligned}
$$

A PV array is a group of many PV cells which are electrically connected in parallel and series circuits in order to generate the required current and voltage. The equivalent circuit for the solar module arranged in $N p$ parallel and Ns series cells is shown in Figure 2.

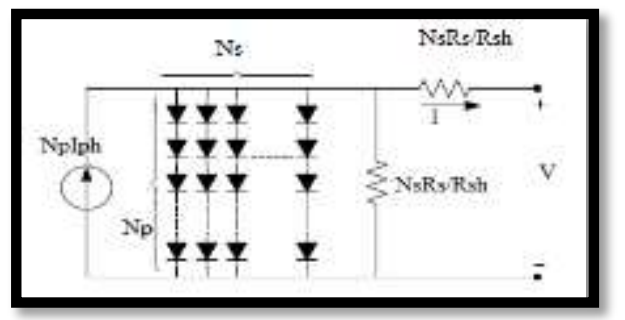

Figure 2. Equivalent circuit of solar array

The terminal equation for the current and voltage of the array becomes as follows

$$
\mathrm{I}=I p h * N p-N p * I o *\left[e^{\frac{q *\left(\frac{\mathrm{V}}{\mathrm{Ns}}+\frac{I R S}{N p}\right)}{K * T C * A}}-1\right]-\left[\frac{\left(\frac{\mathrm{V} * \mathrm{~Np}}{\mathrm{Ns}}+\mathrm{IRs}\right)}{\mathrm{Rsh}}\right]
$$

\subsection{Two-diode PV Model}

The two-diode model has one extra diode as shown in Figure (3). In low irradiance level, the twodiode model is more accurate than the single diode model. The voltage - current relation is given in equation (12). Where Io1 and Io2 are diodes reverse saturation current.

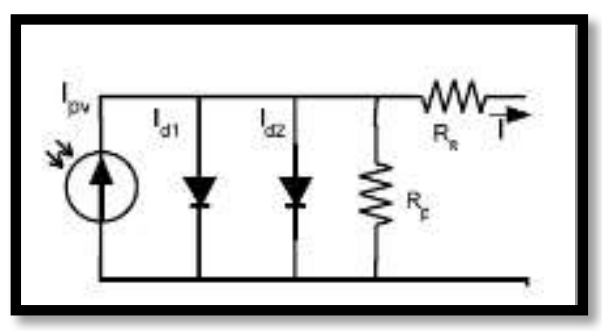

Figure 3. Two-diode model 
$I=I p h-I d 1-I d 2-I s h$

$$
\mathrm{I}=I p h-I o 1 *\left[e^{\frac{q *(V+I R S)}{K * T C * A 1}}-1\right]-I o 2 *\left[e^{\frac{q *(V+I R S)}{K * T C * A 2}}-1\right]-\left[\frac{(\mathrm{V}+\mathrm{IRs})}{\mathrm{Rsh}}\right]
$$

\subsection{Characteristics of Solar Cell}

Based on the equations (1) to (12) and by using MATLAB 2013a the Characteristics of solar cell is shown as below:

Two types of simulation are performed

a. Varying irradiance $\left(1000 \mathrm{w} / \mathrm{m}^{2}, 800 \mathrm{w} / \mathrm{m}^{2}, 600 \mathrm{w} / \mathrm{m}^{2}, 400 \mathrm{w} / \mathrm{m}^{2}, 200 \mathrm{w} / \mathrm{m}^{2}\right)$ and constant temperature $25^{\circ} \mathrm{c}$.

b. Varying temperature $\left(25^{\circ} \mathrm{C}, 30^{\circ} \mathrm{C}, 35^{\circ} \mathrm{C}, 40^{\circ} \mathrm{C}\right.$ and $\left.45^{\circ} \mathrm{C}\right)$ and constant irradiance $1000 \mathrm{w} / \mathrm{m}^{2}$

Figures (4-9) show the simulation results of the I-V and P-V Characteristics for above two conditions. It's clear that, the generated current from the solar cell will be increased by increasing the irradiance of the solar with very small increasing of the generated voltage. On the other hand, when increasing the temperature, the variation values of the generated current and voltage will be small. Solar cell can be more affected with solar irradiance as compared with the temperature effect.

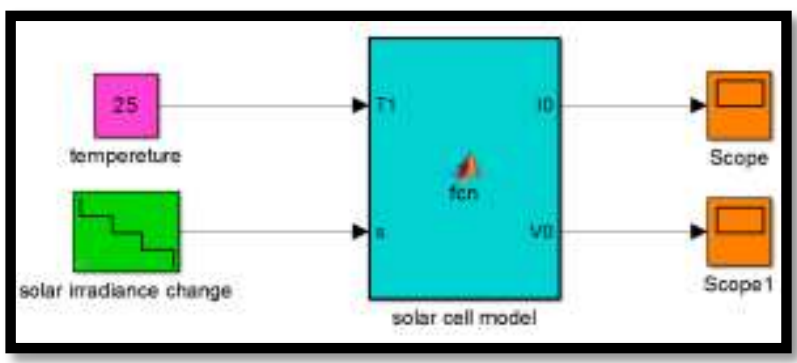

Figure 4. Simulink block of solar cell modeled with change solar irradiance at constant temperature

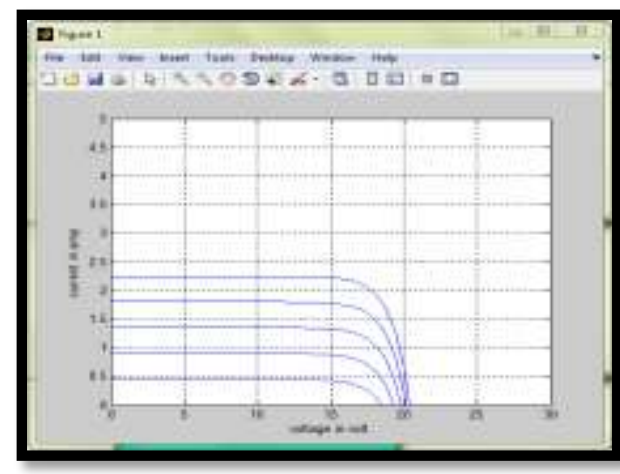

Figure 5. I-V characteristics of solar cell with difference irradiance

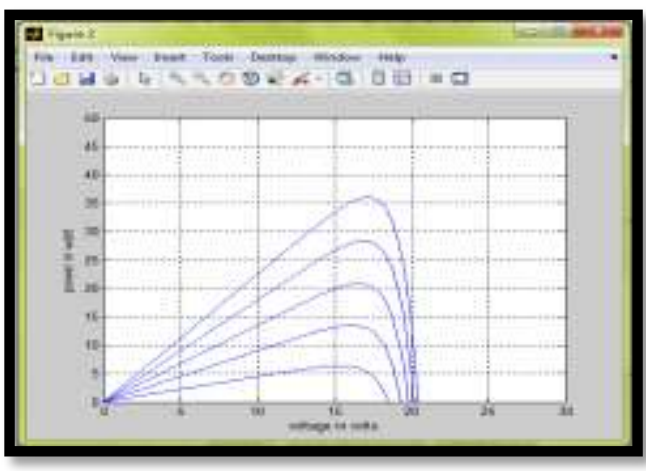

Figure 6. P-V characteristics of solar cell with difference irradiance 


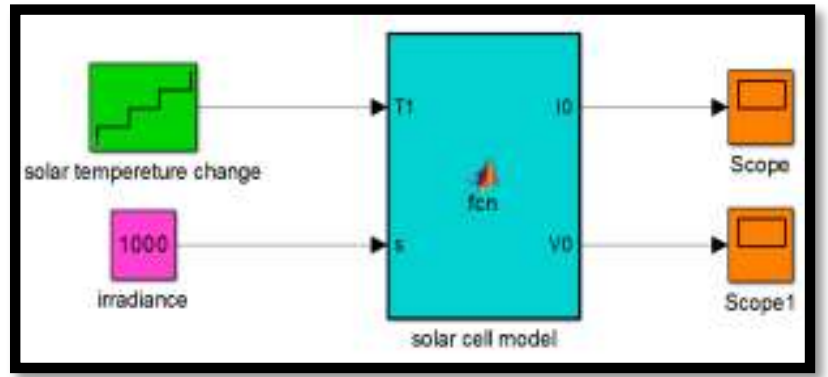

Figure 7. Simulink block of solar cell modeled with change solar temperature at constant irradiance

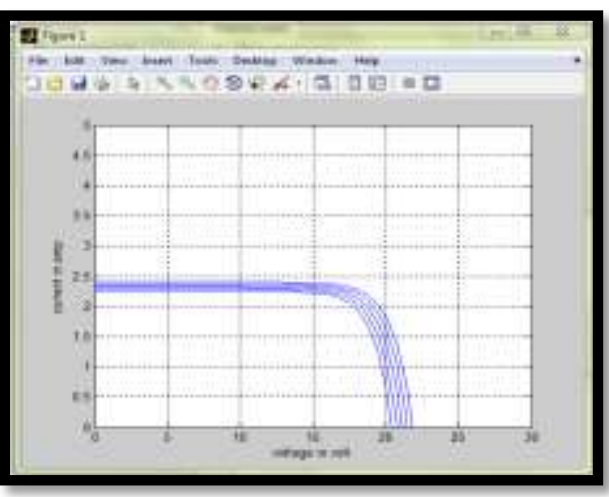

Figure 8. I-V characteristics of solar cell with difference temperature

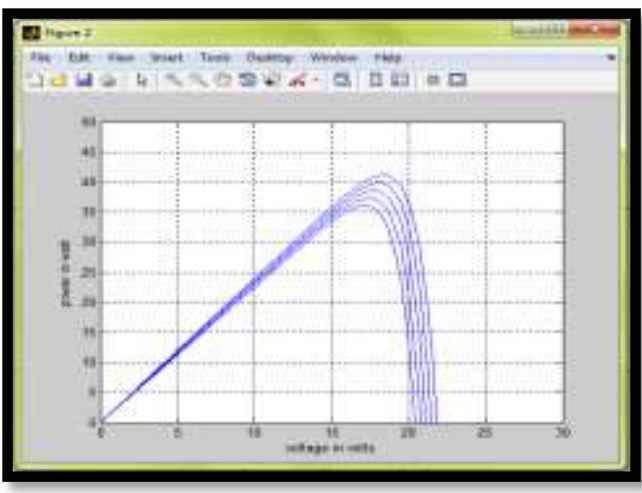

Figure 9. P-V characteristics of solar cell with difference temperature

\section{PROPOSED METHOD}

In this Figure 10 show the proposed system which consists of four LDRs (light dependent sensors), an intelligent controller, ADC0804IC and two DC motors.LDR sensors are used to test the intensity and the direction of the sun which includes (up/ down) and (right/ left) directions.

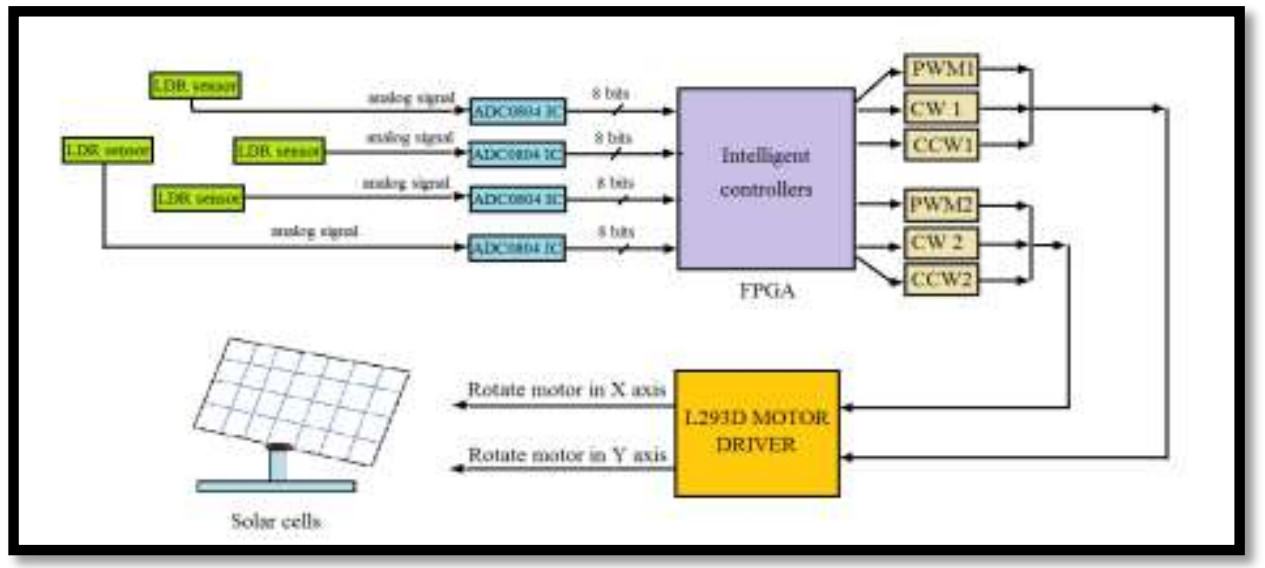

Figure 10. Block diagram for proposed intelligent tracking system

ADC0804IC is used to convert the output signal of the sensors which is analog signal to digital signals as shown in Figure 11. The digital signals will be the input to the intelligent controller which in turns sends signals to control the speed and the direction of the two DC motors. One of these motors is used to track the sun in $\mathrm{X}$-axis direction and the other one is used to track the sun in $\mathrm{Y}$-axis direction. 


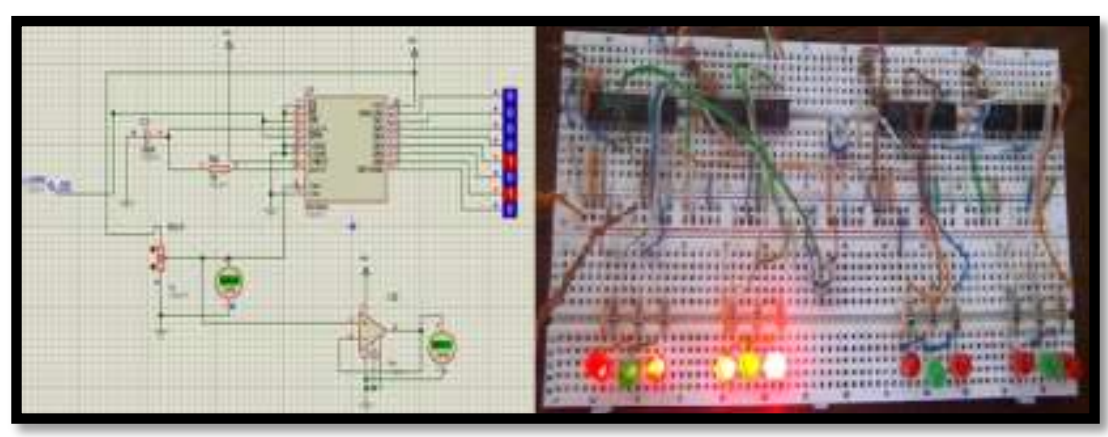

Figure 11. ADC0804IC hardware and simulation results

Simulation results of training ANN with PSO. PSO used in the training of the ANN scheme to obtain best weights for using it in the networks; Figure 12 shows the ANN scheme of the proposed system. There are three output variables in the training data (duty cycle, clockwise rotation, and counter clockwise rotation); in this case, the input processing of the elements includes one neuron, and 10 hidden neurons based on trial and error method.

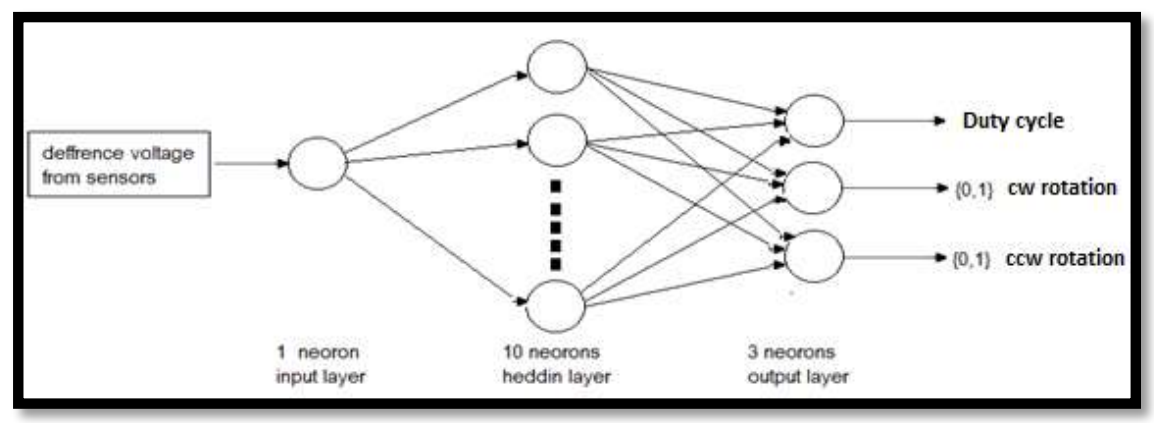

Figure 12. Training ANN using PSO and BP

The performance of the PSO algorithm and the accuracy of this performance shown in Figure 13 and Figure 14.

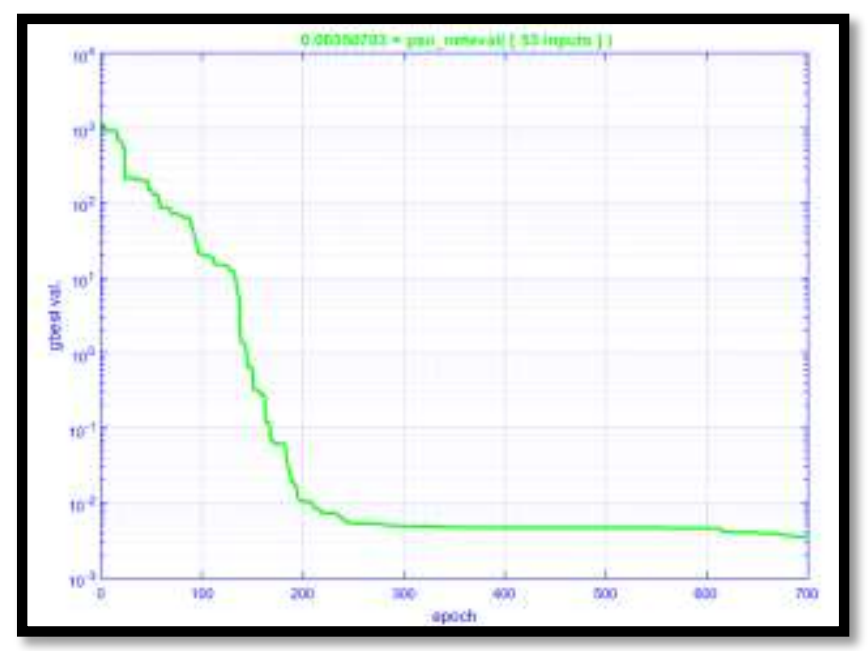

Figure 13. The performance of PSO 


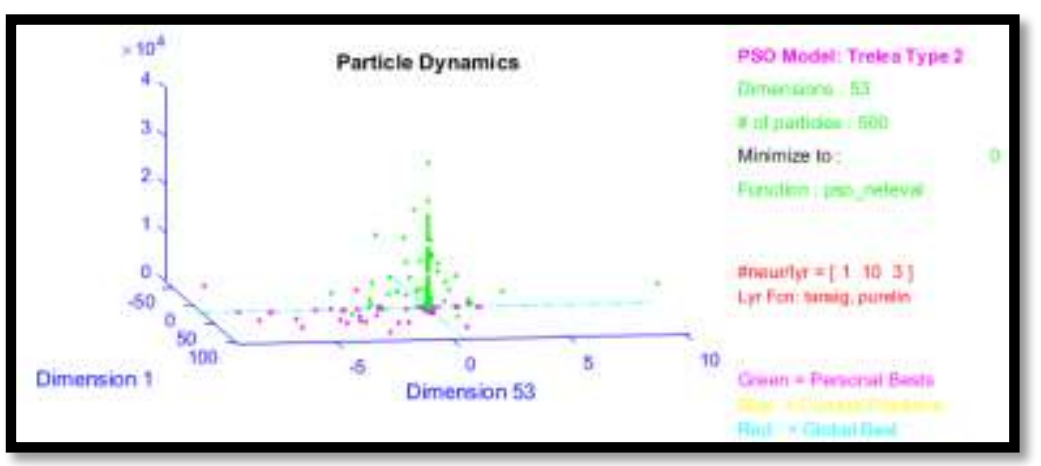

Figure 14. (a) The performance of PSO, (b) the accuracy of performance

After obtaining the weights values of the network by using PSO algorithm; the training results are converted to the SIMULINK for testing them with different situations. Figure 15 shows the Simulink of the proposed system.

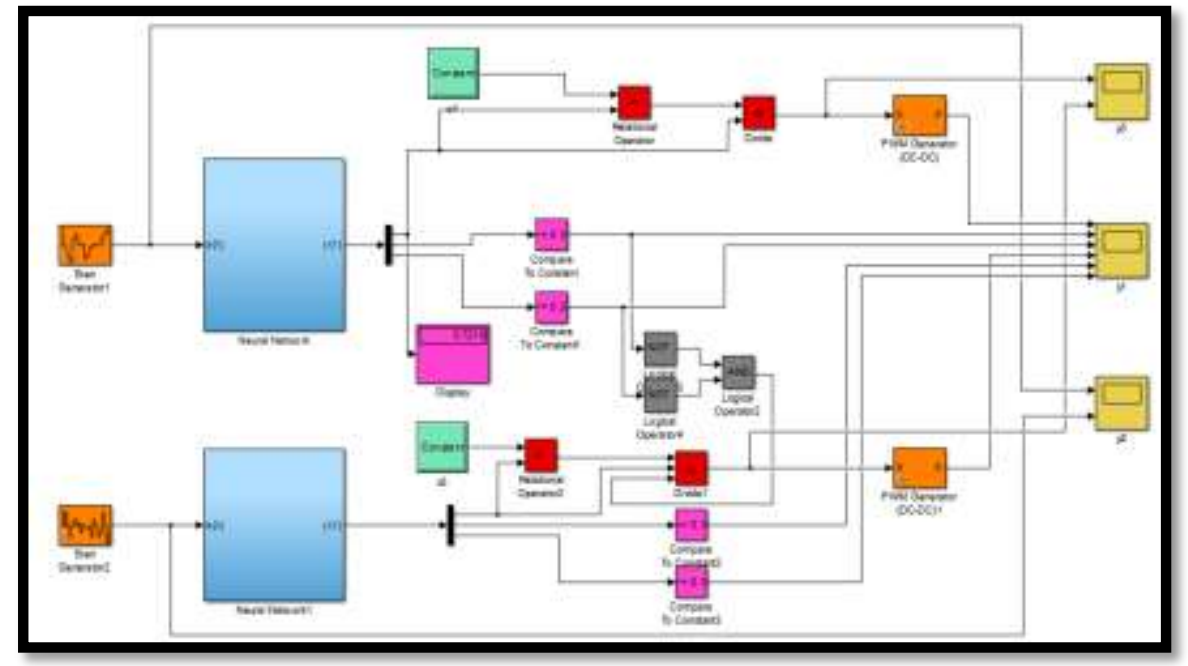

Figure 15. The Simulink of proposed intelligent controller for solar tracking system

The output results of the proposed system are tested with different situation. When the sun light falls on the right corner of the solar cells, the intensity of the light of the LDRs sensor on the right side is greater than the intensity of the light on the left side; thus, the intelligent controller will send three signals (PWM for controlling the speed of rotation, clockwise and counter clockwise) to the DC motor driver(L293D IC) to rotate it in clockwise direction for tracking the sun in $\mathrm{X}$-axis direction, and send another three signals to the motor driver to stop rotation in Y-axis direction. However, when the sun light falls on the left corner of the solar cells results in increasing the intensity of the light of the LDRs sensor on the left side and became greater than the intensity of the light on the right side. Therefore; the intelligent controller will send three signals (PWM for controlling the speed of rotation, clockwise and counter clockwise) to the L293D motor driver to rotate it in counter clock wise for tracking the sun in X-axis direction, and also will send another three signals to the motor driver to stop it from the rotation in $\mathrm{Y}$-axis direction. Furthermore, when the sun light falls on the middle of the solar cells which means the left and right sensors have the same intensity of the light; the intelligent controller will send signals to stop tracking in $\mathrm{X}$-axis direction and start tracking the sun in $\mathrm{Y}$-axis direction. Therefore, if the upper sensor has intensity of light greater than the lower one, the intelligent controller will send signals to rotate the motor in clockwise direction for tracking the sun in Y-axis and the speed of rotation will be controlled by the PWM. And if the upper sensor has light intensity smaller than the lower one, the intelligent controller will send signals to rotate the motor in counter clockwise direction for tracking the sun in Y-axis direction the speed of rotation will be controlled by the PWM. 
Figure 16 shows the different values of the sensors where the $\mathrm{x}$-axis represents the time with different values and the $y$-axis represents the result of subtraction of the amplitude between the (right/left) and (upper/lower) sensors respectively.

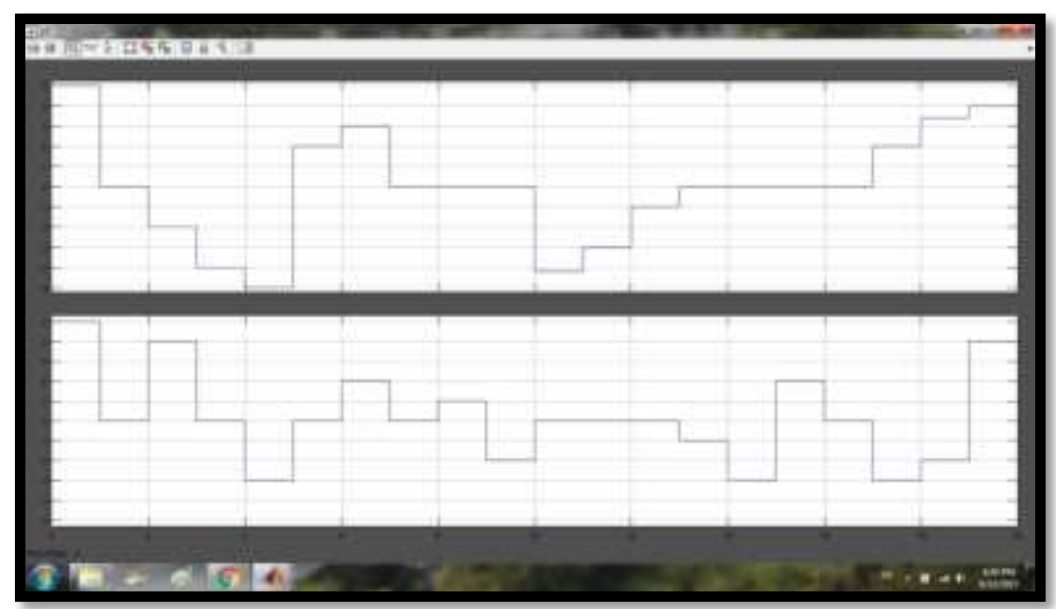

Figure 16. Different states for sensor value

In more details, the speed of rotation of the two motors is controlled by PWM. Also, the duty cycle will be adjusted by the intelligent controller depending on the difference between sensors which means that if the difference value between sensors is too high, the intelligent controller will send duty cycle to rotate the motor faster, and if difference value between the sensors is too low, it will send duty cycle for rotate the motors slower than previously. Figure 17 shows different situation with different duty cycles.

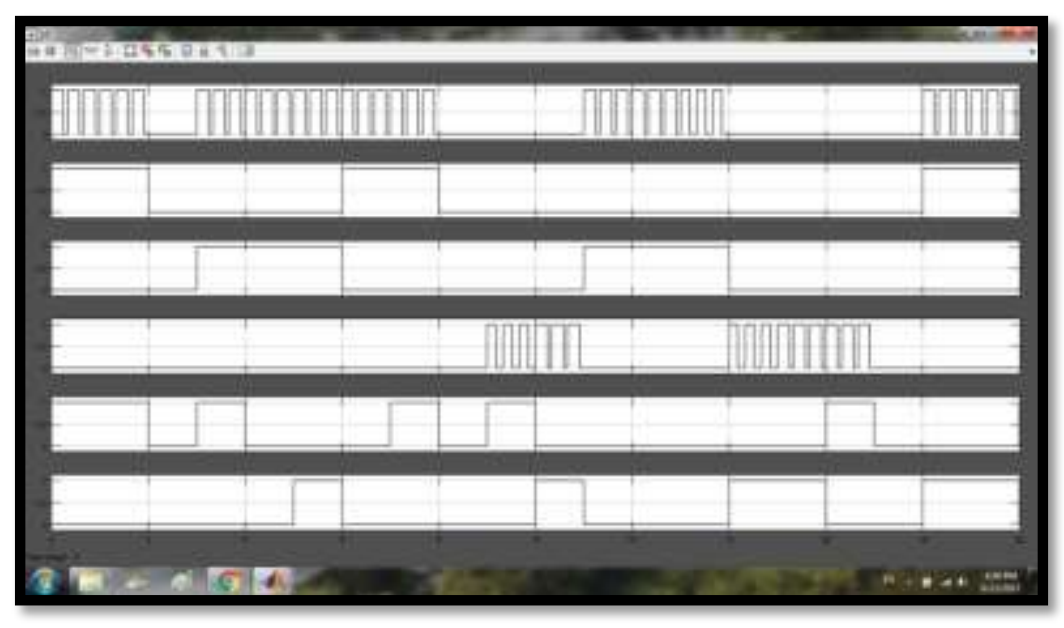

Figure 17. The simulation results for different states of intelligent controller in order to track the sun with times

In order to implement the proposed system on FPGA and simulate the system with ISE 13.3 program, the Simulink of MATLAB converted into VHDL code by HDL coder in MATLAB. Figure 18 shows the RTL of the proposed system in ISE 13.3 after converting it into VHDL code and Figure 19 shows the simulation results of the proposed system, FPGA was used to implement the hardware part. 


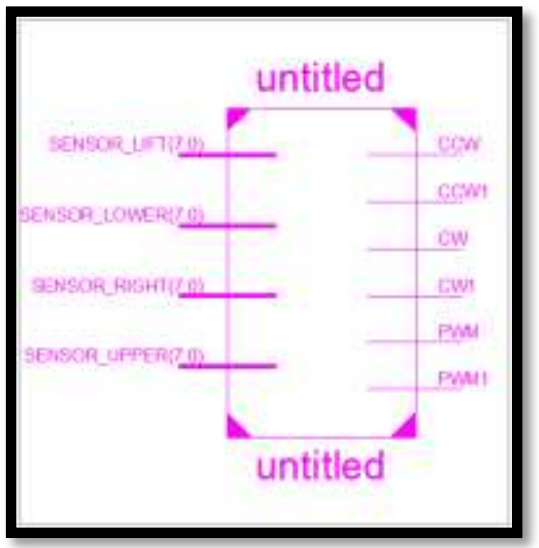

Figure 18. RTL for proposed intelligent system

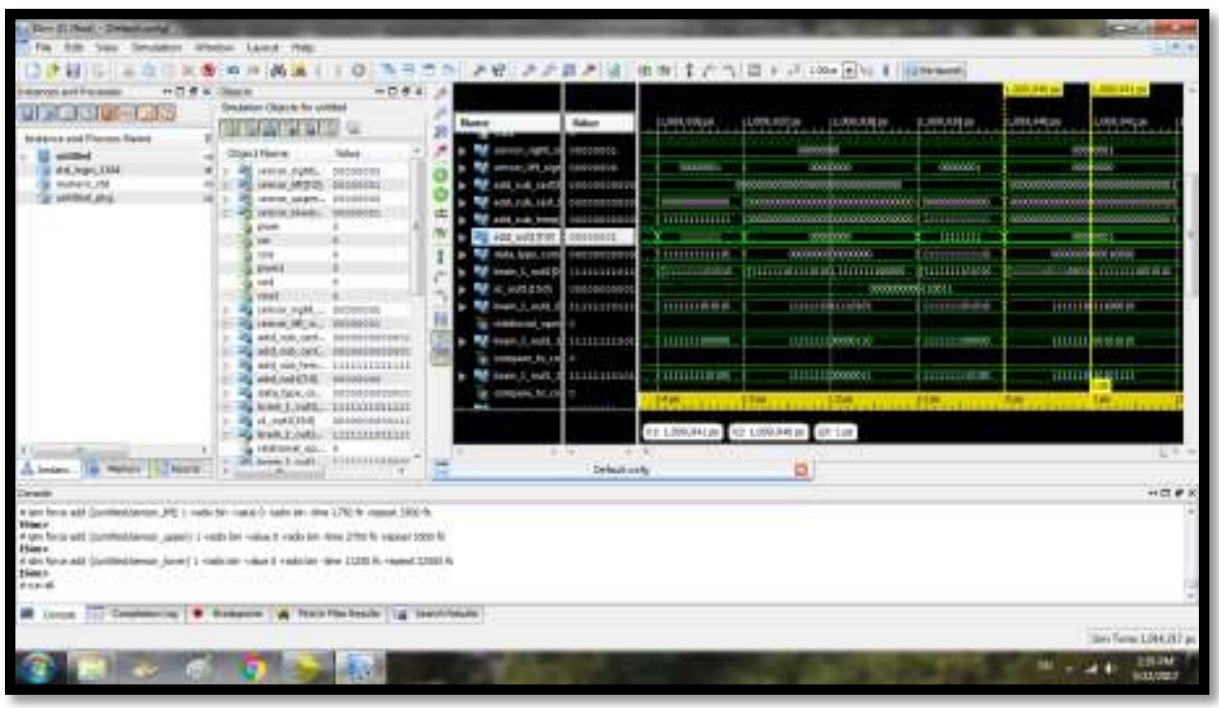

Figure 19. The simulation results of intelligent system

\section{CONCLUSION}

In this paper, solar cell tracking model was proposed and implemented by using MATLAB. This model was tested in different situation to analyze the characteristics of any solar cells through changing simple parameters in the data sheets of the solar cells. PSO algorithm used in the neural network, also FPGA card used for the implementation process that controls the speed of motors and the movements of direction to track the sun light all days

\section{REFERENCES}

[1] X. S Jan Benick, et al., "High-Efficiency n-Type HP mc Silicon Solar Cells", IEEE JOURNAL OF PHOTOVOLTAICS, 2017.

[2] J. P. Xu, J. Fang, H. Zhou, M. Chen, Q. Li, Based on GSM geothermal electricity control system design, International Symposium on Computer, Consumer and Control, 2016.

[3] E. Muljadi, V. Gevorgian, A. Wright, J. Donegan, C. Marnagh, J. McEntee, Electrical Power Conversion of River and Tidal Power Generator, IEEE, 2016.

[4] M. H. Mughal and L. guojie, Review of Pitch Control for Variable Speed Wind Turbine, UIC-ATC-ScalComCBDCom-IoP 2015.

[5] J. Juang and R. Radharamanan, Design of a Solar Tracking System for Renewable Energy, Proceedings of Zone 1 Conference of the American Society for Engineering Education (ASEE Zone 1), 2014. 
[6] Bandam Abhilash, Ashish K Panchal, "Self-Cleaning and Tracking Solar Photovoltaic Panel for Improving Efficiency", International Conference on Advances in Electrical, Electronics, Information, Communication and Bio-Informatics (AEEICB16), 2016.

[7] Djilali Chogueur*, Said Bentouba, Amraoui Merouane, "Smart Sun Tracking System”, IEEE, 2015.

[8] N. C. Sahoo, I. Elamvazuthi, Nursyarizal Mohd Nor, P. Sebastian and B. P. Lim, "PV Panel Modelling using Simscape", IEEE, 2011.

[9] Shah Arifur Ramhman, Rajiv K. Varma, Tim Vanderheide, "Generalized Model of a Photovolatic Panel", IET Renewable Power Generation, 2013.

[10] A. Durgadevi1, S. Arulselvi2 and S.P.Natarajan3, "Photovoltaic Modeling and Its Characteristics", PROCEEDINGS OF ICETECT 2011.

\section{BIOGRAPHY OF AUTHOR}

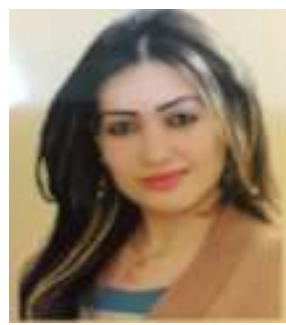

Alaa Hamza Omran, Bachelor of computer engineering /college of engineering /university of Baghdad at 2012, master of electronics and communication /college of engineering /university of Baghdad at 2015.

Currently, working as assist lecturer at university of information technology and communications. 